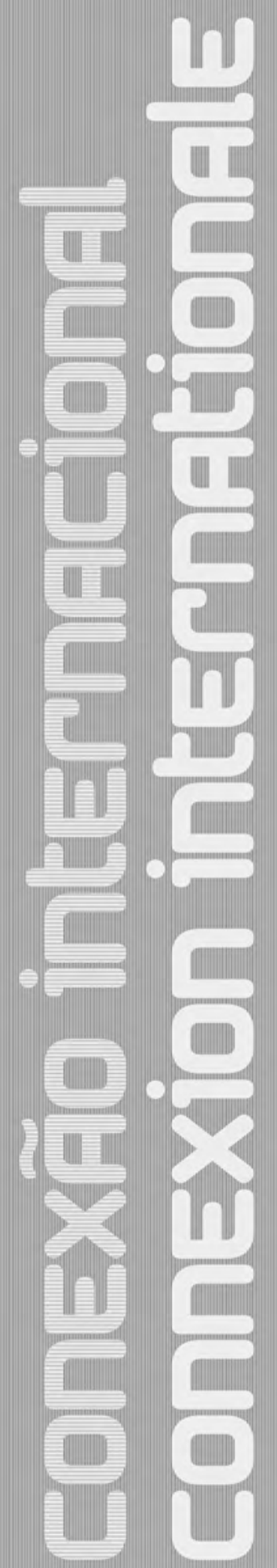





\section{O museu é uma fábrica?}

Hito Steyerl*

Tradução: Beatriz Pimenta Velloso e Alberto Harres

Em 1968, o filme La hora de los Hornos, exibido especificamente em fábricas de forma clandestina, foi um manifesto de grande repercussão do Terceiro Cinema contra o neocolonialismo na América Latina. ${ }^{1}$ Nas fábricas, a cada nova exibição, era pendurado um banner que tinha impresso o seguinte texto: "Todo espectador é um covarde ou um traidor".2 Sessões de cinema cuja principal intenção era quebrar as distinções entre cineasta e público, autor e produtor, para assim criar uma esfera de ação politica.

Hoje, filmes políticos não são mais exibidos nas fábricas. ${ }^{3}$ Eles são mostrados no museu ou na galeria - no espaço da arte. Ou mesmo, em qualquer tipo de cubo branco ${ }^{4}$.

Como isso aconteceu? Primeiramente, o modelo da fábrica fordista tradicional tornou-se obsoleto. ${ }^{5}$ Fábricas foram esvaziadas, suas máquinas embaladas e enviadas para a China. Ex-funcionários treinados novamente, para posterior reciclagem, tornaram-se programadores de software e começaram a trabalhar a partir de suas próprias casas. Posteriormente, o cinema foi transformado quase tão dramaticamente como a fábrica. Ele foi multiplexado, digitalizado, serializado e rapidamente comercializado, na medida em que o neoliberalismo foi se tornando hegemônico em seu alcance e influência. Antes do recente desaparecimento das salas de cinema, filmes políticos procuraram refúgio em outros lugares. Seu retorno ao espaço cinematográfico é bastante recente, considerando que o cinema tradicional nunca foi um espaço aberto à experimentação. Hoje, filmes políticos e experimentais são igualmente mostrados em caixas pretas situadas no interior de cubos brancos - em fortalezas, armazéns, docas e antigas igrejas - onde o som quase sempre é de péssima qualidade.

\footnotetext{
*Hito Steyerl é artista e professora de Novas Mídias na Universidade de Berlin. Imersa no mundo superpovoado de imagens, da escrita
} à produção de filmes e instalações, sua pesquisa aborda questões que envolvem arte, filosofia e política. 
Apesar das projeções de má qualidade e das instalações adaptadas, não obstante estas obras catalisam surpreendentes desejos. Multidões de pessoas podem ser vistas esticando-se e agachando-se, a fim de vislumbrar um filme político ou uma videoarte. Será que esta audiência é vitima dos monopólios das Mídias? Será que estão tentando encontrar respostas diretas para a crise de todas as coisas? Por que estão procurando por essas respostas nos espaços da arte?

\section{Medo do Real?}

A resposta conservadora ao êxodo de filmes políticos (ou de videoinstalações) para o museu é assumir que eles estão perdendo sua relevância. É lamentável ver esses filmes hospedados na torre de marfim burguesa e transformados em alta cultura. Igualmente lastimável é constatar a produção de trabalhos já pensados para serem instalados dentro de um cordão sanitário elitista, que os separa da "realidade». Na verdade, quando Jean-Luc Godard diz que artistas de videoinstalação não deveriam estar com «medo da realidade», naturalmente assume que eles de fato estão. ${ }^{6}$

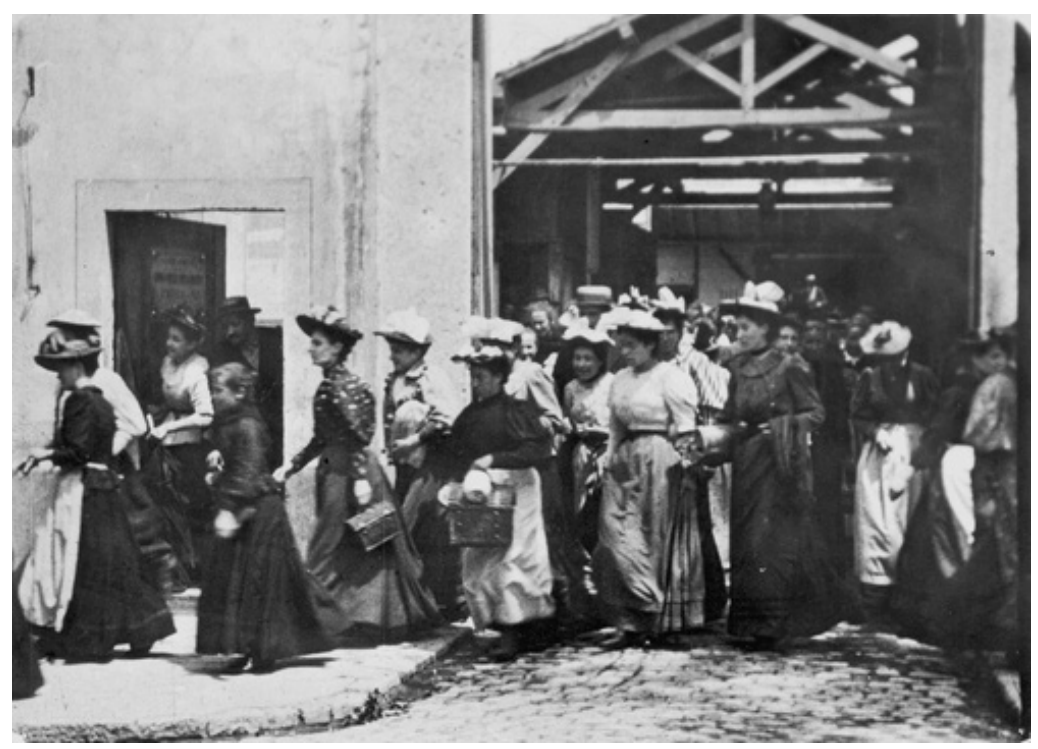

Trabalhadores saem da Fabrica Lumière, Luis Lumière, 1895. 


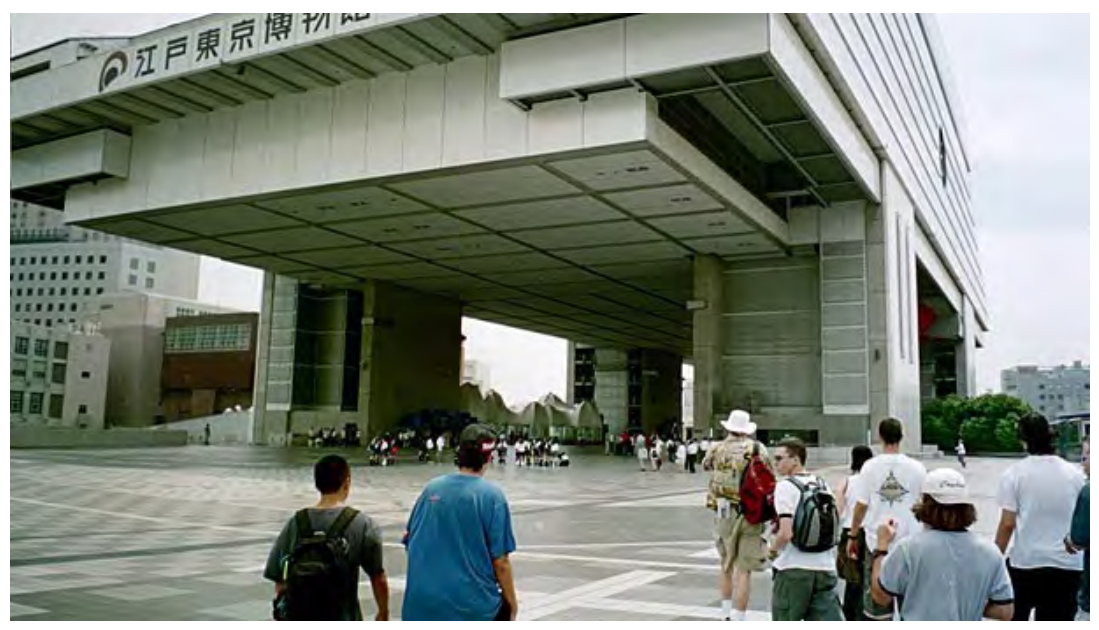

Visitantes entrando no Edo-Tokyo Museum, 2003. Cortesia istaro.

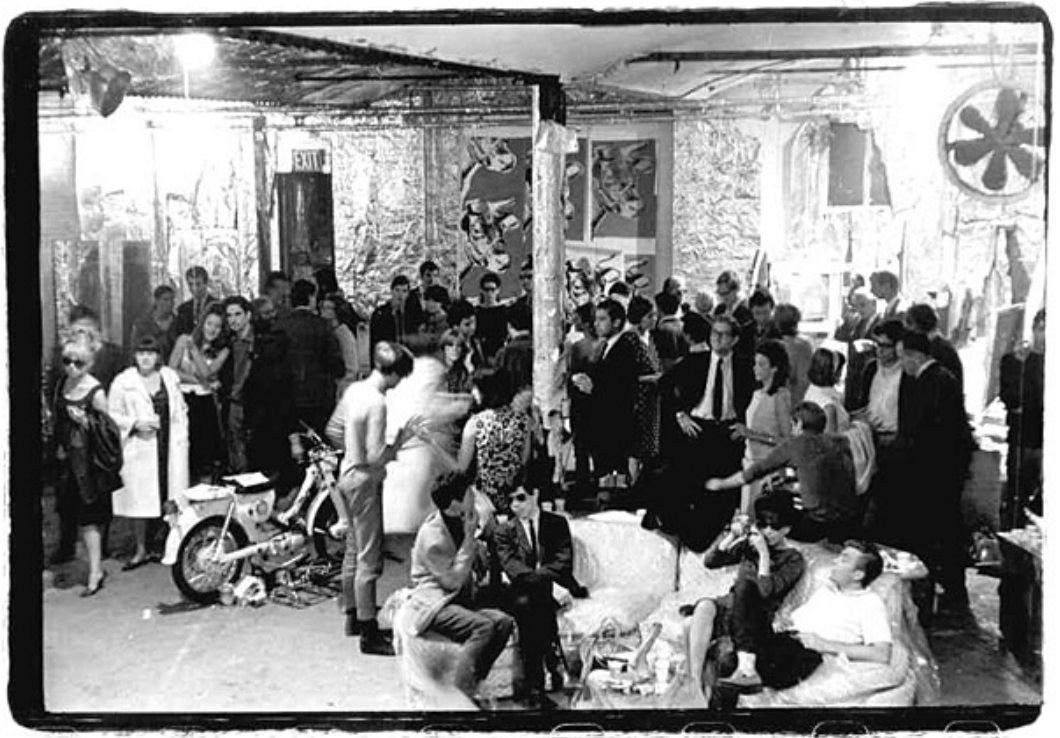

Silver Factory de Andy Warhol 
Onde estaria a realidade, então? Lá fora, além do cubo branco e suas tecnologias de exibição? Como inverter esta afirmação, pouco polêmica, para afirmar que o cubo branco é de fato o real com R maiúsculo? Expor o medo do espaço branco e do vazio interior burgues.

Por outro lado - em sentido bem mais otimista - não há necessidade de recorrer a Lacan, a fim de contestar a acusação de Godard. Mesmo porque o deslocamento da fábrica para o museu nunca aconteceu. Na verdade, os filmes políticos continuam a serem exibidos exatamente no mesmo lugar em que eles sempre foram: em antigas fábricas, que são hoje, frequentemente, museus. Uma galeria, um espaço de arte, um cubo branco com isolamento de som abissal, certamente são espaços que vão continuar mostrando filmes políticos. Mas que também vão incentivar a produção de arte contemporânea. De imagens-jargão, estilos de vida e valores. De valor de exposição, valor de especulação e valor de culto. De entretenimento com força gravitacional. Ou de aura a curta distância. Os funcionários envolvidos nessa produção que é a mais importante provedora da indústria cultural contemporânea são estagiários ansiosos que trabalham de graça.

A fábrica, por assim dizer, continua de forma diferente. É ainda um espaço para a produção, ainda um espaço de exploração e até mesmo de triagem para temas políticos. É um espaço de encontro físico e discussão, às vezes utilizado para trocas mais comuns. No entanto, a fábrica se tornou quase irreconhecível. Então, que tipo de espaço é esse?

\section{Virada produtiva}

A configuração típica do museu-como-fábrica funciona mais ou menos assim. Antes: um local de trabalho industrial. Agora: as pessoas gastam seu tempo de lazer em frente a projeções e TVs. Antes: pessoas trabalhavam nestas fábricas. Agora: as pessoas trabalham em casa na frente a monitores de computador.

A fábrica de Andy Warhol serviu de modelo para o novo museu, em sua transformação produtiva tornou-se uma "fábrica social." (HOLMES: 2004). Hoje, a fábrica social é um gênero que prolifera. $^{7}$

Ela ultrapassa seus limites convencionais e transborda sobre quase tudo ao seu redor. Ela atravessa quartos, camas e sonhos semelhantes, penetra na percepção, convertida em afeto, 


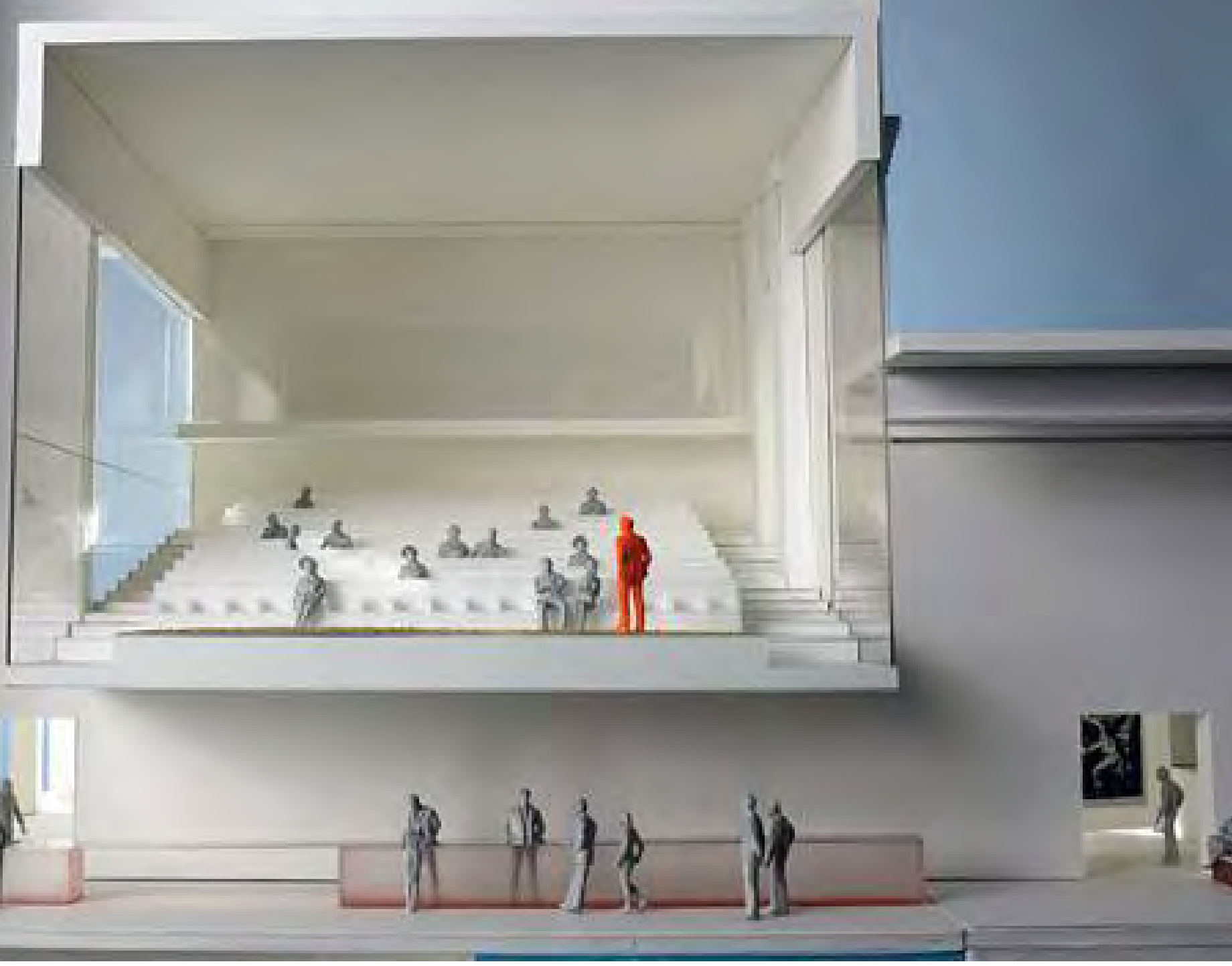

Maquete do Museu de Arte Contemporânea Garage (OMA), a ser construído em uma usina desativada de Moscou, 2006. 
desperta as atenções. Ela transforma tudo o que toca em cultura, senão em arte. Ela é uma "a-fábrica", que faz do afeto um efeito. Ela integra a intimidade, a excentricidade, entre outras formas não convencionais de criação. Esferas públicas e privadas se envolvem em uma zona nebulosa de hiperprodução.

No museu-como-fábrica, algo continua a ser produzido. Instalação, projetos, carpintaria, vendas, discussões e técnicas de manutenção apostam em valores crescentes, e na criação de redes cíclicas suplementares. Um espaço de arte é uma fábrica, que é simultaneamente um supermercado - um casino e um lugar de culto, cujo trabalho (re)produtivo é realizado tanto por senhoras da limpeza como por blogueiros com seus celulares-câmeras. Nessa organização, até mesmo os espectadores são transformados em trabalhadores. Como Jonathan Beller argumenta o cinema e seus derivados (televisão, Internet, etc.) são fábricas, nas quais os espectadores também trabalham. Agora, "ver é trabalhar.» (BELLER: 2002 p. 61) O cinema, que integrou a lógica da produção taylorista da correia transportadora, agora espalha a ideia de fábrica onde quer que ele vá. Entretanto este tipo de produção é muito mais intenso do que o industrial. Trata-se de uma produção que elabora sentidos, a partir de uma mídia que capitaliza as faculdades estéticas e as práticas imaginárias dos espectadores. (BELLER: 2002 p. 67) Nesse sentido, qualquer espaço que integra o cinema e seus sucessores torna-se uma fábrica, e isso, obviamente, inclui o museu. E o cinema instalado em espaços museológicos está de volta às fábricas.

\section{Trabalhadores saindo da fábrica}

É bastante curioso notar que os primeiros filmes feitos por Louis Lumière já mostram trabalhadores saindo da fábrica. No início do cinema, trabalhadores deixam o local de trabalho industrial. A invenção do cinema, assim, tece a relação entre o êxodo de trabalhadores e os modos de produção industrial. Os trabalhadores mesmo deixando o edifício da fábrica, não deixaram os modos de produção para trás. Em vez disso, os levaram junto e os dispersaram em todos os setores da vida humana.

Uma brilhante instalação de Harun Farocki deixa claro para onde os trabalhadores que saem da fábrica são direcionados. Farocki recolhe e instala diferentes versões cinematográficas de trabalhadores saindo da fábrica, a partir da versão silenciosa originada por Louis Lumière até 
as imagens contemporâneas produzidas por câmeras de vigilância. ${ }^{8}$ Os trabalhadores saem das fábricas em vários monitores simultaneamente: de diferentes épocas e em diferentes estilos cinemáticos. ${ }^{9}$ Mas para onde esses trabalhadores estão se dirigindo? Para dentro do espaço da arte, onde o trabalho está instalado.

Farocki não mostra apenas trabalhadores saindo da fábrica, em termos de conteúdo revela uma arqueologia maravilhosa da (não)representação do trabalho; em termos de forma ele aponta para o alastramento da fábrica no espaço da arte. Trabalhadores que deixaram a fábrica e acabaram de entrar em outra: o museu.

Museu que neste caso é a mesma fábrica. Porque a antiga Fábrica Lumière, cujas portas são retratadas no filme original, atualmente é apenas um museu de cinema. ${ }^{10} \mathrm{Em} 1995$, a ruína da antiga fábrica foi declarada monumento histórico e transformada em um local de cultura. A fábrica Lumière, usada para produzir filme fotográfico, é hoje um cinema que tem um espaço de recepção para ser alugado por empresários: "um lugar que agrega história e emoção a seus almoços, coquetéis e jantares». ${ }^{11}$ Hoje, os trabalhadores que deixaram a fábrica, em 1895, são recapturados para dentro do mesmo espaço através da tela do cinema. Eles só deixaram a fábrica para ressurgir dentro dela como um espetáculo.

Quando os trabalhadores saem da fábrica, despertando atenção e emoção, o espaço que entram é o do cinema e da indústria cultural. Como será que os espectadores estão vendo o interior dessa nova fábrica?

\section{Cinema e Fábrica}

Neste ponto, uma diferença decisiva emerge entre o cinema clássico e o museu. Enquanto o espaço clássico de cinema se assemelha ao espaço das fábricas industriais, o museu corresponde ao espaço disperso da fábrica social. Ambos, cinema e fábrica fordista são organizados como locais de confinamento, detenção e controle temporal. Imaginem: Trabalhadores saem da fábrica. Espectadores saem do cinema - uma massa semelhante, disciplinada e controlada num tempo, editado e lançado em intervalos regulares. Como a fábrica tradicional prende seus trabalhadores, o cinema prende o espectador. Ambos são espaços disciplinares e espaços de confinamento. ${ }^{12}$ 
Mas agora imagine: Trabalhadores saindo da fábrica. Espectadores escoando para fora do museu (ou até mesmo em filas para entrar). Uma constelação totalmente diferente de tempo e espaço. Esta segunda multidão não é uma massa, mas uma multidão. ${ }^{13} \mathrm{O}$ museu não organiza uma multidão coerente de pessoas. As pessoas estão dispersas no tempo e no espaço - uma multidão silenciosa, imersa e atomizada, lutando entre a passividade e superestimulação.

Esta transformação espacial é refletida no formato de obras cinematográficas mais recentes. Considerando que as obras cinematográficas tradicionais são compostas por um canal, que concentra o olhar e organiza o tempo, trabalhos mais recentes explodem o espaço. Enquanto a configuração do cinema tradicional funciona a partir de uma única perspectiva central, projeções em tela múltipla criam um espaço multifocal. Enquanto o cinema é uma mídia de massa, as múltiplas telas das instalações são endereçadas a uma multidão espalhada no espaço, ligada apenas por distração, separação e diferença. ${ }^{14}$

A diferença entre massa e multidão surge no limite entre confinamento e dispersão, entre homogeneidade e multiplicidade, entre o espaço do cinema e o espaço da instalação no museu. Esta é uma distinção muito importante, porque ela também irá influenciar no problema do museu como espaço público.

\section{Espaço público}

É óbvio que o espaço da fábrica é tradicionalmente mais ou menos invisível ao público. A sua visibilidade é policiada, e a vigilância produz um olhar em sentido único. Paradoxalmente, um museu não é tão diferente. Em uma entrevista lúcida, em 1972, Godard questionou porque filmar é proibido em fábricas, museus, e aeroportos, uma vez que esta proibição torna $80 \%$ da atividade produtiva na França invisível: "O explorador não mostra a exploração aos explorados. $\|^{15}$ Citação que hoje ainda se aplica, por diferentes razões. Museus proíbem filmagens e fotos ou cobram taxas exorbitantes. ${ }^{16}$ Assim como o trabalho realizado na fábrica não pode ser mostrado fora dela, a maioria das obras em exposição dentro de um museu não pode ser vista além de suas paredes. Uma situação paradoxal surge: se um museu não pode ter visibilidade fora de suas bases de produção e marketing - o trabalho desenvolvido dentro ele é tão publicamente invisível quanto o de qualquer fábrica de salsichas. 



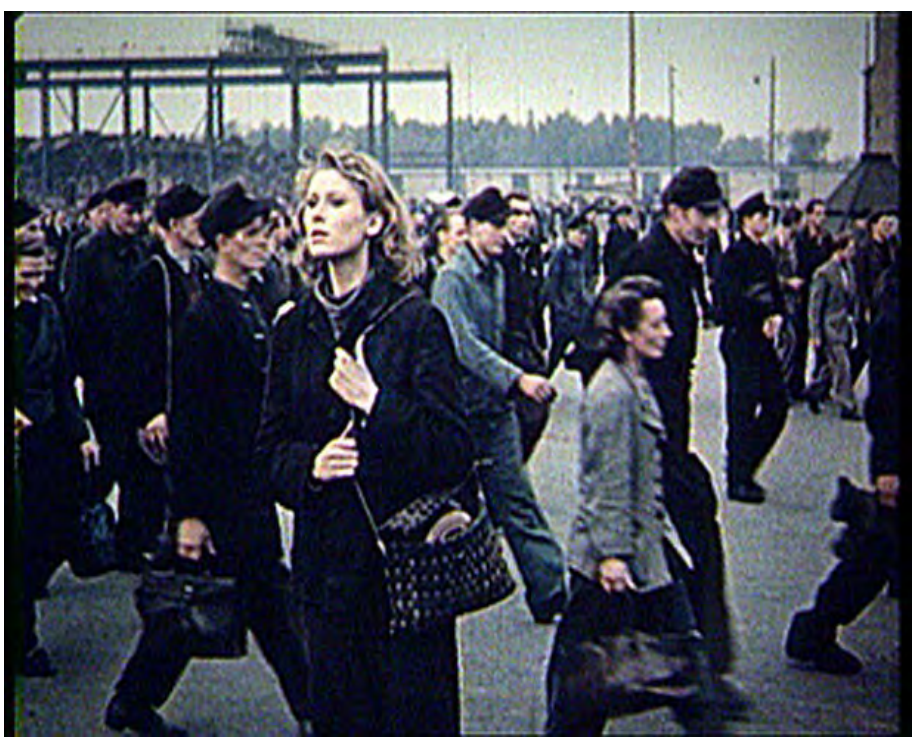

Harun Farocki, Trabalhadores saindo da fábrica em onze décadas, 2006. Frame do vídeo. Cortesia da Leonard \& Bina Ellen Art Gallery.

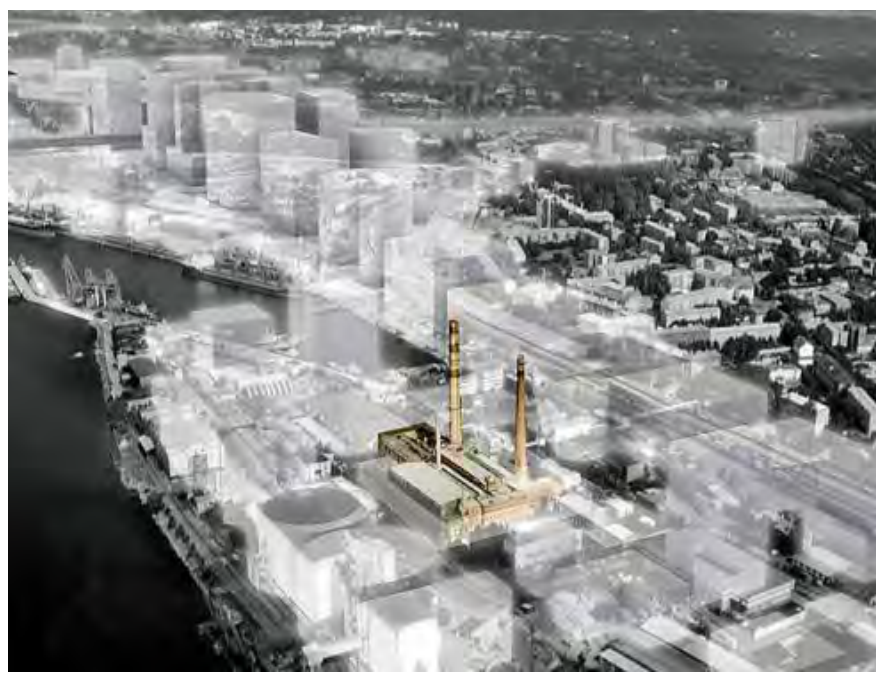

Diagrama (OMA) para o Museu de Arte Contemporânea de Riga, 2006. 
Este controle extremo sobre a visibilidade fica desconfortável ao lado da percepção do museu como um espaço público. O que dizer sobre da invisibilidade do museu contemporâneo como um espaço público? E como a inclusão de obras cinematográficas pode complicar este quadro?

A atual discussão sobre o cinema e o museu como esfera pública está animada. Thomas Elsaesser, por exemplo, pergunta se o cinema no museu poderia constituir um último remanescente da esfera pública burguesa (ELSAESSER: 2009). Jürgen Habermas delineou as condições desta arena em que as pessoas falam, e por sua vez outras respondem, todas participando juntas do mesmo discurso racional, igual e transparente em torno do problema entre o publico e o privado. (HABERMAS:1991) Na realidade, o museu contemporâneo é uma cacofonia - instalações retumbam simultaneamente, mas ninguém escuta. Para piorar a situação, o modo temporal com que muitas instalações cinematográficas funcionam se opõe ao discurso verdadeiramente compartilhado em torno delas; se as obras são muito longas, os espectadores simplesmente as abandonam. O que seria visto como um ato de traição em um cinema - sair de uma projeção antes dela terminar - torna-se o comportamento padrão em qualquer situação de instalação espacial. No espaço da instalação de museu, os espectadores realmente se tornaram treinadores-traidores da própria duração cinematográfica. No que circulam através do espaço, os espectadores são editores ativos, zappiando combinam fragmentos - efetivamente executam uma co-curadoria da exposição. Racionalmente compartilhar impressões sobre as obras tornou-se algo quase impossível. E a esfera pública burguesa? Para além dessa esfera idealizada, o museu contemporâneo representa uma realidade não realizada.

\section{Sujeitos soberanos}

No mesmo sentido, Elsaesser expressa a dimensão não democrática deste espaço. No qual o cinema está dramaticamente preso - em suspensão, sob licença, ou mesmo se mantendo sob uma sentença suspensa - o cinema sobrevive a seu próprio custo, preservado sob "custódia protetora" (Elsaesser : 2009). Custódia protetora não é um simples aprisionamento. Ela se refere a um estado de exceção ou (pelo menos) de suspensão temporal da legalidade que permite a suspensão da própria lei. Este estado de exceção também é abordado no ensaio de Boris Groys "Politics of Installation" (GROYS: 2009). Com base nos escritos de Carl Schmitt, Groys atribui 
ao artista o papel de soberano - um estado de exceção - violentamente estabelecido por uma lei própria para "aprisionar" um espaço com a forma de uma instalação. O artista como soberano, na sequencia, deve assumir o papel de fundador da esfera pública da exposição.

À primeira vista, esta ideia repete o velho mito do artista como gênio louco, ou mais precisamente, como ditador pequeno-burguês. Mas o ponto é: se isso funcionou bem como modo de produção artística, tornou-se prática padrão em qualquer fábrica social. Daí, a ideia de que dentro do museu, quase todo mundo tenta se comportar como um soberano lou ditador pequeno-burguês)? Afinal, a multidão dentro dos museus é composta de soberanos concorrentes: curadores, espectadores, artistas, críticos.

Vamos ver mais de perto o espetador-como-soberano. Ao julgar uma exposição, muitos tentam assumir o compromisso de soberania comum ao tradicional sujeito burgues, que tem o objetivo de (re)masterizar a mostra para domar a multiplicidade incontrolável de seus significados, pronunciar um veredicto, e atribuir valor. Mas, infelizmente, a duração cinematográfica inviabiliza a postura desse sujeito. Ela deixa todos os fragmentos do filme a cargo de trabalhadores - incapazes de obter uma visão geral de todo o processo de produção. Muitos - principalmente os críticos - saem frustrados de mostras de arquivo sem poder suportar a abundância do tempo cinematográfico. Lembre-se dos ataques mordazes sobre o alongamento de filmes e vídeos na Documenta 11? A multiplicação da duração cinematográfica explodiu o ponto de vista do julgamento soberano. Também tornou impossível a reconfiguração do eu através de uma subjetividade fixa. O cinema no museu dificulta descrição, avaliação e pesquisa. Impressões parciais dominam o quadro. O trabalho do espectador não pode mais ser ignorado, deve ser reconhecido como mestre do julgamento. Sob estas circunstâncias, um discurso transparente, informativo, inclusivo torna-se difícil, senão impossível.

O cinema deixa claro que o museu não é uma esfera pública, apontando o problema de sua falta de visibilidade - torna esta falta pública. Em vez de preencher o espaço do museu, o cinema conserva a sua ausência. Despertando, simultaneamente, o desejo e o potencial de realizar alguma coisa dentro desse espaço.

Como uma multidão, o público opera sob a condição de invisibilidade parcial, acesso incompleto, realidades fragmentadas - de mercantilização clandestina. Transparência, descrição e o olhar soberano tornam-se opacos sobre uma nuvem de acontecimentos. O próprio cinema 
explode em multiplicidade - Arranjos em telas múltiplas espacialmente dispersas não podem mais ser contidos por um único ponto de vista. O quadro completo, por assim dizer, permanece indisponível. Há sempre algo que falta - as pessoas perdem partes da sequencia, o som não funciona. A tela em si ou qualquer ponto de vista a partir do qual o filme poderia ser visto não existem.

\section{Ruptura}

Sem aviso prévio, a questão do cinema político foi invertida. O que começou como uma discussão sobre cinema político no Museu se transformou em uma questão de política cinematográfica em uma fábrica. Tradicionalmente, o cinema político estava destinado a educar. «Realidade» foi um esforço instrumental da «representação», para atingir os seus efeitos foi medida em termos de eficiência, de revelação revolucionária, de ganhos de consciência, ou de potencial disparador de ação.

Hoje, as políticas cinematográficas são pós-representacionais. Elas não educam a multidão, mas a produzem. Elas articulam a multidão no espaço e no tempo. Submergindo-a em invisibilidade parcial, em seguida orquestram sua dispersão, movimento e reconfiguração. Elas organizam a multidão sem pregar para ela. Elas substituem o olhar do espectador soberano burgues do cubo branco pela visão incompleta, obscurecida, fraturada, e oprimida do espectador-como-trabalhador.

Porém há um aspecto que vai bem além dessa ideia. O que mais faltaria nestas instalações cinemáticas? ${ }^{17}$ Voltemos ao caso liminar da Documenta 11, no qual se constatou que nenhuma pessoa seria capaz de ver todo o material cinematográfico exposto, mesmo que se estivesse presente nos 100 dias em que a exposição foi aberta ao público. Não existe um único espectador que poderia afirmar ter sequer visto tudo, muito menos ter esgotado os significados deste volume de material. É óbvio o que está faltando neste programa de ação: uma vez que nenhum espectador pode, eventualmente, fornecer sentido a tal volume de imagens, ele apela para a multiplicidade de espectadores. Na verdade, a exposição só poderia ser vista por uma multiplicidade de pontos de vista, que, sempre seriam anexadas a visões de outros. Só se os guardas noturnos e vários espectadores trabalhassem juntos, em turnos, todo o material cinematográfico da Documenta 11 poderia ser visualizado. Mas, a fim de entender o que (e como) ele foi visto, os diversos espectadores deveriam se reunir para estabelecer possí- 
veis sentidos. Essa atividade compartilhada é completamente diferente da de espectadores narcisistas, que olham para si mesmo e uns aos outros no interior das exposições - trata-se simplesmente de não ignorar a obra de arte (ou de trata-la como mero pretexto), mas de leva-la a outro nível.

O cinema dentro do museu exige, portanto, um olhar múltiplo, que já não é coletivo, mas comum, que é incompleto, mas em processo, que é distraído e singular, mas que pode ser editado em várias sequências e combinações. Esse olhar não é mais o olhar do indivíduo mestre e soberano, nem, mais precisamente, do soberano auto iludido (mesmo que "só por um dia", como David Bowie cantou). Nem sequer é produto do trabalho comum, apenas foca seu ponto de ruptura com o paradigma da produtividade. O museu-como-fábrica em sua política cinematográfica interpela na multiplicidade a impossibilidade e ausência de significados definidos. Contudo, ao deflagrar essa falta, simultaneamente, suscita o desejo de pensar a partir dessa nova condição.

\section{Política cinematográfica}

Isto significa que hoje todas as obras cinematográficas se tornaram políticas? Ou, mais, ainda há alguma diferença entre as diferentes formas de política cinematográfica? A resposta é simples. Qualquer trabalho cinematográfico convencional irá sempre tentar reproduzir uma configuração já existente: a projeção de um público, que absolutamente não é público, no qual participação e exploração tornam-se indistinguíveis. Entretanto, uma articulação cinematográfica politica pode tentar fazer algo completamente diferente.

Afinal, o que desesperadamente falta no museu-como-fábrica? Uma saída. Se a fábrica está em toda parte, não há então mais nenhuma porta para sair dela - não há maneira de escapar a sua implacável produtividade. O cinema político poderia então se tornar a tela através da qual as pessoas pudessem sair do museu-como-fábrica-social. Mas em que tela esta saída poderia ter lugar? Certamente, sobre uma que atualmente está em falta.

Este texto foi publicado pela primeira vez e-flux jornal \# 7, 2009

(C) 2009 e-flux e o autor 


\section{Notas}

1 O filme La Hora de los Hornos, de 1968, realizado pelos cineastas argentinos Fernando Solanas e Octavio Getino, impulsionou o desenvolvimento de um circuito alternativo de exibição através da fundação do Grupo Cine Liberación

2 Em citação ao livro Os condenados da Terra, de Frantz Fanon.

3 Ou vídeos ou instalações de vídeo/filme. Para fazer corretamente as distinções (que existem e são importantes) exigiria outro texto.

4 Estou ciente do problema de tratar todos estes espaços como similares.

5 Pelo menos nos países ocidentais.

6 O contexto do comentário de Godard é uma conversa - aparentemente um monólogo - com artistas jovens, a quem ele repreende pelo uso do que chama de dispositivos tecnológicos em exposições. Ver "Debrief de conversations avec Jean-Luc Godard," the Sans casser des briques blog, March 10, 2009.

7 Sabeth Buchmann cita Hardt e Negri: "A 'fábrica social' é uma forma de produção que toca e penetra todas as esferas e os aspectos da vida pública e privada, de produção e comunicação de conhecimento," In "From Systems-Oriented Art to Biopolitical Art Practice," NODE. London.

8 Há um grande ensaio sobre este trabalho escrito por Harun Farocki, "Workers Leaving the Factory," in Nachdruck/Imprint: Texte/ Writings, trans. Laurent Faasch-Ibrahim (Berlin: Verlag Vorwerk, New York: Lukas \& Sternberg, 2001), reprinted on the Senses of Cinema Web site.

9 Essa descrição refere-se à instalação realizada na Generali Foundation show, "Kino wie noch nie" (2005).

$10 \mathrm{Na}$ época da sua fundação o Instituo Lumière declarou: "Hoje a locação do primeiro filme está preservada e abriga um cinema de 270 lugares, aonde os trabalhadores e trabalhadoras da fábrica, os espectadores, vão ao cinema no local de sua invenção".

11 O espaço comporta 250 pessoas sentadas ou aproximadamente 300 pessoas de pé, Institut Lumière.

12 Há, porém, uma diferença interessante entre cinema e fábrica: no cenário reconstruído do Museu Lumière, a abertura do ex-portão está bloqueada por um painel de vidro transparente para indicar o enquadramento do início do filme. Espectadores que saem são obrigados a contornar este obstáculo, e sair pela antiga localização do próprio portão, que não existe mais. Assim, a situação atual é como um negativo da anterior: as pessoas são bloqueadas pela ex-abertura, que se transformou em uma tela de vidro; elas têm que sair através das antigas paredes da fábrica, que agora estão parcialmente desaparecidas. Veja fotos em http://www.institut-lumiere. org/actualit\%C3\%A9s/sorties-d'usine-2017.html

13 Para uma descrição mais profunda do conceito geralmente bastante vago de multidão, ver Paolo Virno A Grammar of the Multitude, trans. Isabella Bertoletti, James Cascaito and Andrea Casson (New York and Los Angeles: Semiotexte, 2004). Disponível em português no link http://www.c-e-m.org/wp-content/uploads/gramatica-da-multidao.pdf

14 Como fazer múltiplos arranjos a em uma única tela.

15“"Tout va bien", filme de Gordard, 1972.

16 Fotografia e filmagem de vídeo normalmente não são permitidas na Tate. No entanto, as filmagens são bem-vindas a partir de uma base comercial, com taxas de localização a partir de £200 por hora. A política no Centro Pompidou é mais confusa: pode-se filmar ou 
fotografar obras de coleções permanentes (que você vai encontrar no $4^{\circ}$ e $5^{\circ}$ andares e no Atelier Brancusi) para o seu próprio uso pessoal. Entretanto, não se pode fotografar ou filmar obras que têm um ponto vermelho, como também usar flash ou tripé.

17 Um bom exemplo seria "Democracies", de Artur $₫$ mijewski, uma instalação de telas múltiplas dessincronizadas, com trilhões de possibilidades de combinação entre conteúdos de tela.

\section{Referências}

BELLER, Jonathan L, "Kino-I, Kino-World," in The Visual Culture Reader, ed. Nicholas Mirzoeff ,London and New York: Routledge, 2002.

EISAESSER, Thomas "The Cinema in the Museum: Our Last Bourgeois Public Sphere?" In International Film Studies Conference, "Perspectives on the Public Sphere: Cinematic Configurations of 'I' and 'We,'" Berlin, Germany, April 23-25, 2009.

GROYS, Boris, "Politics of Installation," e-flux journal, no. 2, January 2009

HABERMAS,Jürgen. The Structural Transformation of the Public Sphere: An Inquiry into a Category of Bourgeois Society, trans. Thomas Burger with the assistance of Frederick Lawrence. Cambridge, MA: The MIT Press, [1962] 1991.

HOLMES Brian, "Warhol in the Rising Sun: Art, Subcultures and Semiotic Production," 16 Beaver ARTicles, August 8, 2004 